\title{
El invernadero del hôtel Saccard como impulsor de la intriga en La Curée de Émile Zola ${ }^{1}$
}

\section{María Custodia Sánchez Luque \\ Universidade Federal do Maranhão}

Resumen: Este artículo tiene por objetivo analizar el tratamiento dado por Zola al tema del jardín en la novela La Curée, ${ }^{2}$ desde el punto de vista de los lazos que se tejen entre el invernadero del palacete Saccard, que más que un simple decorado se revela como un verdadero actante que interviene en la intriga, y los protagonistas de la obra. Con este propósito efectuamos un análisis detallado del discurso poético de las dos descripciones de este espacio, de los capítulos I y IV del texto. Dicho análisis se centra en tres aspectos: el jardín en tanto que lugar de ensueño, de liberación espiritual y de salida del tiempo; el paralelismo entre el jardín y el alma humana, así como la relación arquitectura-naturaleza.

Palabras clave: Zola, jardín, geopoética, multidisciplinaridad

Résumé: Cet article a pour but d'analyser le traitement donné au jardin d'hiver par son auteur dans le roman La Curée, du point de vue des liens qui se tissent entre la serre de l'hôtel Saccard, qui plus qu'un simple décor se révèle comme un véritable actant qui intervient dans l'intrigue, et les personnages principaux du roman. Dans ce but, nous faisons une analyse détaillée du discours poétique dans les deux descriptions de la serre de l'hôtel Saccard, dans les chapitres I et IV du texte. Cette analyse se concentre sur trois aspects: le jardin comme lieu de rêverie, de libération spirituelle et de sortie du temps; le parallélisme entre le jardin et l'âme humaine, ainsi que le rapport entre architecture et nature.

Mots-clés: Zola, jardin, géopoétique, multidisciplinarité 


\section{Introducción}

Siguiendo las premisas de la geopoética, que preconiza el final de la compartimentación entre la literatura y el resto de las disciplinas, el estudio taxonómico y físico del invernadero del hôtel Saccard nos ayuda a entender el simbolismo de las descripciones que se hacen de él, así como el desarrollo actancial de la obra.

Para concebir este jardín cerrado, el autor se inspiró en los invernaderos del Jardín de Plantas de París. Ahora bien, creemos que Zola no habría tenido la inspiración de un invernadero con las características técnicas del evocado en La Curée, con ese calor húmedo que propicia la frondosidad tropical; con esa impresión de recalentamiento interno, intensificada por el frío exterior, y con esos olores penetrantes a savia y a vainilla, de no haber sido por el progreso técnico y científico que ayudó a los agricultores europeos en su adaptación a las nuevas necesidades botánicas. En efecto, a partir de 1820 se produce una serie de conquistas técnicas que revolucionan las posibilidades de construcción de los invernaderos (Alain, Y.-M. 2017: 66-67). A saber, el perfeccionamiento del trabajo del hierro y de fundición de calidad; la realización del vidrio pulido, menos espeso, más luminoso y fabricado en paneles de grandes dimensiones, así como el dominio de la temperatura gracias a la calefacción por termosifón (Allain, Y.-M./ Christiany, J. 2010: 100).

Es necesario insistir en la mención de estos avances tan presentes en el invernadero del hôtel Saccard, ya que sin ellos no se podría hablar, por ejemplo, de un aspecto tan importante para comprender el desarrollo simbólico y actancial del relato, como es el calor.

Como se verá más adelante, el asunto del calor evoca el del fuego, factor clave en la atmósfera caliente y malsana que se respira en este invernadero. Asimismo, el fuego es metáfora tanto de las carencias afectivas de Renée, como de la monstruosidad del incesto entre ella y su hijastro Maxime. Este "amour immense, [ce] besoin de volupté [...] où bouillait la sève ardente des tropiques" (La Curée: 75) no hubiera podido alcanzar su paroxismo en ningún otro lugar que no fuera este invernadero; razón por la que consideramos que la elección de este espacio por Zola no fue en absoluto fruto del azar.

El conocimiento del universo vegetal en Zola permite entrever una serie de temas que se repiten de manera constante, entre los que se encuentran el jardín en tanto que lugar 
de ensueño, de liberación espiritual y de salida del tiempo; el paralelismo entre el jardín y el alma humana, así como la relación arquitectura-naturaleza. Son estos los tres aspectos sobre los que trata este análisis. Si bien nos centraremos en las dos grandes descripciones del invernadero de los capítulos I y IV, su estudio nos llevará a establecer constantes paralelismos con el discurso poético de otros pasajes de la obra, dado que las descripciones del invernadero resumen las imágenes que se dispersan por toda la novela.

\section{El jardín como lugar de ensueño, de liberación espiritual y de salida del tiempo}

Al abordar este asunto, volvemos a la necesidad de apoyarnos en la descripción física. La primera presentación que hace Zola del invernadero, en el capítulo I, se concibe como un recorrido que comienza en el estanque central, desde donde se puede acceder a distintos senderos e hileras de árboles, sin que ninguno de estos senderos tenga más protagonismo que el otro, ofreciendo una multitud de perspectivas, en una puesta en escena destinada a reproducir el rico desorden de las selvas tropicales de donde proceden las plantas que han sido instaladas allí: el bambú, las palmeras, el ravenala o el bananero, entre otras. Esto contribuye a crear un ambiente exótico, con un cierto componente evasivo, que transporta al lector. Para lograr este efecto de extrañamiento era necesario olvidarse de las perspectivas, liberarse de la obligación de correspondencia con la realidad.

El invernadero del hôtel Saccard se nos presenta como un espacio indiferente a las leyes del tiempo y del espacio y a los puntos de referencia morales y sociales. No en vano, cuando Renée y su hijastro Maxime se hacen amantes, va a ser este su lugar de encuentro preferido, porque solo aquí la pareja se siente transportada a un mundo ajeno al suyo, tal como se desprende del siguiente pasaje: «Et ils étaient à mille lieues de Paris, en dehors de la vie facile du Bois et des salons officiels, dans le coin d'une forêt de l'Inde, de quelque temple monstrueux, dont le sphinx de marbre noir devenait le dieu» (La Curée: 20).

El hecho de que las dos grandes descripciones del invernadero se presenten, desde el punto de vista narrativo, como relatos autónomos con respecto al resto de la novela refuerza la idea del jardín como lugar de liberación espiritual (Sánchez Luque, M.-C. 2016).

Este contexto impregnado de exotismo hace que expresiones no metafóricas en una 
lectura aislada, resulten metafóricas debido a la fuerza paradigmática. Así, ciertos nombres de plantas como «Pandanus de Java», «Bambou de l'Inde», «Euphorbes d'Abyssinie», «Coques du Levant», «Hibiscus de la Chine», «Tanguin de Madagascar», y de otros objetos provenientes de países lejanos como «Sphinx de marbre noir», «Écrans chinois», o «Gravures japonaises», en los que la mención al país de origen, que podría ser entendida en otro contexto como la lógica alusión al lugar de procedencia, imprescindible para identificar de qué planta u objeto se trata, son interpretados aquí como evocaciones intencionadas de países remotos, para potenciar el efecto de enajenación. Se trata de casos límite que muestran cómo las coacciones sobre el eje paradigmático alcanzan la esfera de actividad de la metáfora hasta el eje sintagmático (Sánchez Luque, M.-C, opus cit.).

Asimismo, tanto la metonimia «... un Ravenala, l'arbre du voyageur, dressait son bouquet...» (La Curée: 73) como la comparación «les Palmiers, légèrement penchés dans leur grâce, épanouissaient leurs éventails, étalaient leurs têtes arrondies, laissaient pendre leurs palmes, comme des avirons lassés par leur éternel voyage» (Ibídem), sugieren la noción de viaje.

La comparación de las hojas de caladium con alas de mariposa contribuye también a intensificar esa impresión de extasiamiento: «les Caladiums, dont les feuilles en fer de lance, blanches et à nervures vertes, ressemblent à de larges ailes de papillon» (Ibídem). Al evocar y transmitir impresiones sensuales de una manera tan penetrante, Zola enlaza con la estética simbolista.

Este afán por sugerir lo exótico y lejano para subrayar la idea de jardín como espacio capaz de hacernos sentir transportados, encuentra su paralelismo en una serie de metáforas marinas que se muestran en otros pasajes de la novela. La vista del mar nos encara con lo desconocido, nos incita a viajar; frente a lo desconocido nace el deseo de conocer. Encontramos la primera de estas metáforas en la descripción del parque Monceau desde la ventana de la habitación de Renée, en el capítulo I:

En bas le parc, une mer d'ombre roulait. Les masses couleur d'encre des hauts feuillages secoués par de brusques rafales avaient un large balancement de flux et de reflux, avec ce bruit de feuilles sèches qui rappelle l'égouttement des vagues sur une plage de cailloux. (La Curée: 53) 
La segunda se presenta en el capítulo II, en ese pasaje tan emblemático de la novela, en el que Saccard contempla la ciudad de París desde Montmartre: «Puis, la nuit se fit, la ville devint confuse, on l'entendit respirer largement, comme une mer dont on ne voit plus que la crête des vagues» (La Curée: 106).

La tercera aparece en el fragmento que describe la vista desde la ventana del café Riche, la noche del primer encuentro amoroso entre Renée y Maxime: «Les arbres découpaient leurs branches hautes sur un ciel clair, tandis que la ligne irrégulière des maisons se perdait avec les amoncellements d'une côté rocheuse, au bord d'une mer bleuâtre» (La Curée: 173).

Por otro lado, Nadia Beaudoin destaca el carácter de esta relación amorosa como flor de invernadero incapaz de sobrevivir fuera del terreno parisino, en una naturaleza «natural» (Beaudoin, N., 1998). De ahí el aburrimiento que invade a la pareja cuando se traslada a la playa en verano:

Lorsque la mode les força absolument de quitter Paris, ils allèrent aux bains de mer, mais à regret, pensant sur les plages de l'Océan aux trottoirs des boulevards. Leur amour lui-même s'y ennuya. C'était une fleur de la serre qui avait besoin du grand lit gris et rose, de la chair nue du cabinet, de l'aube dorée du petit salon. Depuis qu'ils étaient seuls, le soir, en face de la mer, ils ne trouvaient plus rien à se dire (La Curée: 213).

\section{Paralelismo entre el jardín y el alma humana}

Coincidimos con Isabel Veloso cuando afirma que en casi todas las obras de Zola el espacio adquiere unas condiciones antropomórficas, convirtiéndose en actante que no solo participa en el conflicto sino que determina las condiciones del resto de los personajes y la dinámica del texto, presidiendo simbólicamente toda la obra (Veloso, I., 1993: 253). También Jean-François Tonard indica que los lugares cerrados constituyen en Zola un depósito de imágenes arquetipales, cuyo análisis permite descubrir y examinar la intención primera del autor (Tonard, J.-F., 1994: 11). Bajo el influjo del invernadero, Renée no solo ha sido capaz de ceder a la transgresión de convertirse en amante de su hijastro, sino también de tornarse en una mujer fatal. Como apunta Jean-Claude Charvoz, la comunión de la 
protagonista con el lugar es tan fuerte, que las cualidades de una y otro se intercambian y se tejen unos lazos de amistad y complicidad tan sólidos que convierten al medio en solidario de la caída (Charvoz, J.-C., 1980: 102-104).

En esta sección analizamos toda una serie de metáforas de las descripciones del invernadero, en torno al tema del fuego:

\begin{tabular}{|c|c|}
\hline $\begin{array}{l}\text { 1ª DESCRIPCIÓN DEL INVERNADERO } \\
\text { CAPITULO I }\end{array}$ & $\begin{array}{l}\text { 2ª DESCRIPCIÓN DEL INVERNADERO } \\
\text { CAPITULO IV }\end{array}$ \\
\hline $\begin{array}{l}\text { «et c'était [le grand sphinx de marbre] comme } \\
\text { l'Idole sombre, aux cuises luisantes, de cette } \\
\text { terre de feu» (La Curée: } 74) \text {. }\end{array}$ & $\begin{array}{l}\text { «Longtemps ils demeurèrent sans gestes et sans } \\
\text { paroles, dans ce bain de flammes» } \\
\text { (La Curée: } 200) \text {. }\end{array}$ \\
\hline $\begin{array}{l}\text { «cet épanouissement de forêt, ce tas de } \\
\text { végétations, toutes brûlantes des entrailles qui } \\
\text { les nourrissaient» (La Curée: } 75 \text { ). }\end{array}$ & $\begin{array}{l}\text { «La serre aimait, brûlait avec eux» } \\
\text { (La Curée: 201). }\end{array}$ \\
\hline $\begin{array}{l}\text { «A cette heure de vision nette, toutes ses } \\
\text { bonnes résolutions s'évanouissaient à jamais, } \\
\text { l'ivresse du dîner remontait à sa tête, } \\
\text { impérieuse, victorieuse, doublée par les } \\
\text { flammes de la serre» (La Curée: } 76) .\end{array}$ & $\begin{array}{l}\text { «La chaleur était suffocante, une chaleur } \\
\text { sombre, qui ne tombait pas du ciel en pluie de } \\
\text { feu, mais qui traînait à terre, ainsi qu'une } \\
\text { exhalaison malsaine» (La Curée: 200). }\end{array}$ \\
\hline $\begin{array}{l}\text { Metafórico debido a la fuerza paradigmática: } \\
\text { «Ses sens de femme ardente, ses caprices de } \\
\text { femme blasée s'éveillaient» (Ibídem). }\end{array}$ & $\begin{array}{l}\text { «ce coin de forêt vierge où flambaient les } \\
\text { verdures et les floraisons des tropiques» } \\
\text { (Ibídem). }\end{array}$ \\
\hline $\begin{array}{l}\text { «le désir longtemps fuyant, «l'autre chose» } \\
\text { vainement cherchée par Renée dans le } \\
\text { bercement de sa calèche, dans la cendre fine de } \\
\text { la nuit tombante, et qui venait brusquement de } \\
\text { lui révéler sous la clarté crue, au milieu de ce } \\
\text { jardin de feu, la vue de Louise et de Maxime, } \\
\text { riant et jouant, les mains dans les mains ...» } \\
\text { (Ibídem.) }\end{array}$ & $\begin{array}{l}\text { «Elle [Renée] n’était plus qu'une fille brûlante } \\
\text { de la serre» (Ibídem). }\end{array}$ \\
\hline
\end{tabular}


Como pone de relieve Jean-François Tonard, la atmósfera malsana y caliente del invernadero parece facilitar la explosión de monstruos vegetales, la vegetación arde y el estanque se transforma en un mar de fuego que recuerda al caldero de bruja de L'Assommoir (Tonard, J.-F., opus cit: 68).

Becker y Lavielle asocian la presencia del elemento ígneo en las descripciones del invernadero con la complejidad psicológica del personaje de Renée: al igual que Fedra, la heroína de La Curée se siente quemada por un fuego devorador. Las expresiones «lueur de braise» o «coucher du soleil à demi-éteint», que son descriptivas en un primer nivel, introducen en un segundo nivel, el tema del fuego, del mito de Fedra, nieta de Helios, el Sol, a través de su madre Pasifae. Renée es, como Fedra, un ser de fuego, devorado por deseos incandescentes. Coincidimos con este punto de vista, pero relacionamos, además, la presencia del fuego con otra faceta fundamental de la personalidad de Renée: la de sus grandes carencias emocionales.

Zola nos informa de que Renée ha sido privada de la necesaria atención afectiva desde una edad muy temprana, debido a la falta de relación con su madre o con una figura que la reemplace. Desde su infancia, Renée ha buscado el calor y la luz para llenar este vacío, de ahí que encontremos en la obra una serie de pasajes en los que la mujer tiene frío. Ya desde el principio se nos presenta en actitud friolera, tapada con una manta de piel en el interior de la calesa: «Elle attira frileusement à elle un coin de la peau d'ours qui emplissait l'intérieur de la voiture d'une nappe de neige soyeuse» (La Curée: 41). En otros pasajes aparecen manifestaciones como «Elle se fit faire un grand feu» (La Curée: 175); «Elle grelottait, il lui fallait des brasiers ardents, une chaleur suffocante qui lui mettait un front de petites gouttes de sueur» (La Curée: 185), o «Moi qui ai toujours froid» (La Curée: 283).

Al mismo tiempo, constatamos que Renée se siente muy sola, lo que la lleva a un estado psicológico de avidez emocional y de búsqueda desaforada de experiencias nuevas. Razón por la cual el invernadero juega un papel esencial al paliar su falta de calor afectivo.

Asimismo, el hôtel Béraud, asociado a la infancia de la protagonista, es presentado como un lugar frío. Zola traduce el conflicto oponiendo a la hija y al padre mediante una serie de calificativos que describen sus respectivos lugares: «Zola's symbolism calls for no 
very subtle interpretation: the chilliness, the silence, the wintry pallor of this island house, contrasting with the heat and clamour of the city, point to Renée's past which is in conflict with her present» (Hemmings, F.M.J., apud Tonard, J.-F., opus cit: 136).

En la obra de teatro que Zola escribe a partir de La Curée, titulada Renée, M. Béraud explica a su hija que su madre no está muerta en realidad, sino que se ha fugado con un amante. En la novela, Zola se limita a una simple alusión: «Sa femme était morte jeune. Quelque drame secret, dont la blessure saignait toujours, dut assombrir encore la figure du magistrat» (La Curée: 97).

El frenesí sensual que late en el interior de Renée atestigua una falta de verdadero equilibrio, falta, sobre todo, de calor sentimental. Ella no lo encontró en su padre ni en Saccard. Unas palabras de la tía Elizabeth, a raíz del incidente que desencadena el embarazo de Renée, indican que ella sospecha que su sobrina no ha tenido el afecto suficiente: «Ses préférences pour Christine la désolaient, et elle pensait que, si elle avait également gardé Renée près d'elle, la pauvre enfant n'aurait pas succombé» (Joly, B. 1977: 60).

Al llegar a este punto se impone referir la importancia de la imagen materna en la mentalidad de Zola. A esta concepción de Zola, según la cual la mujer ideal es la madre, contribuyeron tanto las influencias de la época - en efecto, en el siglo XIX la mujer fue idealizada en tanto que madre - como sus circunstancias personales. Desde su infancia a su vida adulta, Zola estuvo principalmente rodeado de mujeres, dado que su padre murió cuando él solo tenía siete años: su abuela materna, su madre, su esposa Alexandrine, y su amante Jeanne Rozerot. La huella que estas mujeres dejaron en el escritor determinó su percepción de la vida. Encontramos que Zola busca resaltar la ausencia de la figura materna en Renée, con todo lo que esto puede llegar a tener de perturbador para el desarrollo emocional, al ser dicha figura la encargada de entablar los vínculos afectivos intensos.

\section{Relación arquitectura-naturaleza}

Dicha relación se articula en el imaginario del novelista como un enfrentamiento. En el caso del invernadero del palacete Saccard, Zola quiere que sea la naturaleza la que salga triunfante de esa lucha y nos dirige este mensaje: ni siquiera cuando el hombre se empeña 
en arrancar la vegetación de su hábitat natural para encerrarla en una caja de cristal, puede impedir que esta escape a su control, que crezca de forma monstruosa y que sea capaz de influir en el comportamiento de los que la frecuentan, así como de adquirir características de seres animados, tanto como si se encontrara en estado de libertad.

Con este triunfo de la naturaleza del invernadero, Zola permite que esta se tome, de alguna manera, su revancha por el riesgo de desaparición en el que se encuentra el bosque francés en esos momentos, debido a la especulación inmobiliaria. Así, con una serie de imágenes metafóricas, afirma el poder generador de la vegetación contraponiéndolo a la corrupción del Segundo Imperio.

Como escriben Becker y Lavielle, Zola retoma la oposición romántica entre la ciudad infernal, lugar de perdición, y la naturaleza regeneradora (Becker, C./ Lavielle, V., 1999: 103). Para esclarecer este planteamiento, desarrollamos la metáfora de las armas blancas, que evoca toda la serie de heridas y mutilaciones que se le infligirán a la ciudad de París con ocasión de las reformas del plan Haussmann:

\begin{tabular}{|l|l|}
\hline $\begin{array}{l}\text { 1a DESCRIPCIÓN DEL INVERNADERO } \\
\text { CAPITULO I }\end{array}$ & $\begin{array}{l}\text { 2- DESCRIPCIÓN DEL INVERNADERO } \\
\text { CAPITULO IV }\end{array}$ \\
\hline $\begin{array}{l}\text { «les Caladiums, dont les feuilles en fer de lance, } \\
\text { blanches et à nervures vertes, ressemblent à de } \\
\text { larges ailes de papillon» } \\
\text { (La Curée: 73). }\end{array}$ & $\begin{array}{l}\text { «et les feuilles blanches, en fer de lance, des } \\
\text { Caladium mettaient une suite vague de } \\
\text { meurtrissures et de pâleurs» (La Curée: 201). }\end{array}$ \\
\hline $\begin{array}{l}\text { «Près du bord, un Pandanus de Java } \\
\text { épanouissait sa gerbe de feuilles verdâtres, } \\
\text { striées de blanc, minces comme des épées, } \\
\text { épineuses et dentelées comme des poignards } \\
\text { malais» (La Curée: 73). }\end{array}$ & \\
\hline
\end{tabular}

Podemos relacionar estas metáforas con las que aparecen en un pasaje del capítulo II de la novela, en el que el especulador inmobiliario Saccard describe, desde el balcón de un restaurante en Montmartre, lo que sería su idea de reforma de la ciudad: 
de sa main étendue, ouverte et tranchante comme un coutelas, il fit signe de séparer la ville en quatre parts. - Tu veux parler de la rue de Rivoli et du nouveau boulevard que l'on perce? demanda sa femme. - Oui, la grande croisée de Paris, comme ils disent. [...] Les tronçons agoniseront dans le plâtre... Tiens, suis un peu ma main. Du boulevard du Temple à la barrière du Trône, une entaille; puis, de ce côté, une autre entaille, de la Madeleine à la plaine Monceau; et une troisième entaille dans ce sens, une autre dans celui-ci, une entaille là, une entaille plus loin, des entailles partout. Paris haché à coups de sabre, les veines ouvertes, [...] Sa main sèche et nerveuse coupait toujours dans le vide. Angèle [sa femme] avait un léger frisson, devant ce couteau vivant, ces doigts de fer qui hachaient sans pitié l'amas sans bornes des toits sombres. [...] La petitesse de cette main, s'acharnant sur une proie géante, finissait par inquiéter; et, tandis qu'elle déchirait sans effort les entrailles de l'énorme ville, on eût dit qu'elle prenait un étrange reflet d'acier, dans le crépuscule bleuâtre (La Curée: 106).

En consonancia con el título de la novela, la villa de París es una presa que se disputan los especuladores, sobre todo Saccard, un cuerpo despedazado por el Plan Haussmann. Esta metáfora exige, según Rabaté, una mirada desde arriba, un plan de conjunto de la ciudad (Rabaté, E., 1989: 115). En este fragmento de la novela, la ciudad es comparada con una presa gigante a la que se perfora, se hiere, se le abren las venas. Rabaté llama la atención sobre la fuerza de la paranomasia «entaille/entraille".

\begin{tabular}{|l|}
\hline «Et da sa main étendue, ouverte et tranchante comme un coutelas» \\
\hline «une entaille» \\
\hline «une autre entaille» \\
\hline «et une troisième entaille» \\
\hline «des entailles Partout» \\
\hline «Paris haché à coups de sabre» \\
\hline «les veines ouvertes» \\
\hline «Angèle avait un léger frisson, devant ce couteau vivant» \\
\hline «ces doigts de fer qui hachaient sans pitié» \\
\hline «comme si la main de son mari eût réellement fait les entrailles» \\
\hline «laissant derrière elle [la main de Saccard] de longues et affreuses blessures» \\
\hline «s'acharnant sur une proie géante» \\
\hline «déchirait sans effort les entrailles» \\
\hline
\end{tabular}


Asimismo, esta metáfora de la descripción de París desde Montmartre, en la que la ciudad es presentada como una presa abierta en canal, es evocada más adelante en la novela, cuando se describe la inspección de un grupo de hombres, entre los que se encuentra Saccard, a un conjunto de casas derrumbadas a causa de los planes urbanísticos. Esta evocación se produce tanto desde el punto de vista del discurso poético, con expresiones como «Les pans de murs crevés par la pioche» (La Curée: 296), o «De hautes bâtisses éventrées, montrant leurs entrailles blafardes» (Ibídem), como desde el punto de vista sintagmático:

Saccard semblait réjoui par cette promenade à travers des ruines. Il venait de se rappeler le dîner qu'il avait fait jadis, avec sa première femme, sur les buttes Montmartre, et il se souvenait parfaitement d'avoir indiqué, du tranchant de sa main, l'entaille qui coupait Paris de la place du Château-d'Eau à la barrière du Trône. La réalisation de cette prédiction lointaine l'enchantait. Il suivait l'entaille, avec des joies secrètes d'auteur, comme s'il eût donné lui-même les premiers coups de pioche, de ses doigts de fer. (La Curée: 299)

Lo expuesto por Juan Calatrava, en su artículo «Jardines de Émile Zola», también viene a avalar esta idea de una relación problemática entre naturaleza y arquitectura en Zola, al afirmar que en el Paradou de La Faute de l'abbé Mouret, la naturaleza, antaño sometida por la mano del hombre, no se ha limitado simplemente a recuperar sus derechos, sino que lo ha hecho de un modo excesivo, tomándose su revancha. «El otrora parque aristocrático de la época de Luis XV, se ha convertido en el escenario de un crecimiento salvaje de la naturaleza, que ha arruinado todas las construcciones humanas, revelando así la fragilidad y el carácter efímero del orden que originariamente se le quiso imponer» (Calatrava, J., 2011: 102-102). En Le Docteur Pascal, uno de los personajes de la novela rememora el Paradou, calificándolo como un espacio ya en trance de desaparición ante el acoso de la ciudad moderna. En uno de sus antiguos edificios se ha instalado un molino de vapor, pero lo más desgarrador es que el antiguo jardín exuberante ha sido ya talado para ser parcelado: la mano del hombre ha vuelto a imponerse sobre el efímero rebrote de la naturaleza salvaje que había podido albergar la historia del abate Mouret y Albine. Cuando 
Clotilde recuerda vagamente haber oído hablar de la historia de su primo Serge, la respuesta del doctor Pascal viene a ser que tales historias ya no son posibles en el marco de la ciudad moderna (Ibídem: 114). En Le Rêve, la relación entre arquitectura y naturaleza está marcada por las ruinas del castillo medieval de Hautecoeur, «escenario de paseos campestres en los que la vida vegetal que recubre sus viejas piedras sustenta una nueva versión de la poética de las ruinas» (Got, 0., 2002, apud Calatrava, J., opus cit.: 101). Esta reflexión, que conecta con la idea del jardín romántico, tan salpicado de ruinas medievales, nos induce a pensar que quizás la recreación de este tipo de paisajes sea la única forma de reconciliación entre naturaleza y arquitectura posible para Zola.

\section{Conclusión}

El conocimiento de la obra zoliana nos lleva a considerar las relaciones entre las distintas materias como campo de creación multidisciplinar. La glorificación y la exaltación de la naturaleza son tan inmensas en Zola, que cuando se dispone a transcribirlas en palabras, se olvida de las barreras entre las diferentes áreas del conocimiento, de forma que resulta difícil delimitar lo que procede de la botánica, de la literatura o del arte. No es de extrañar, por lo tanto, que empecemos nuestro ensayo refiriéndonos a la descripción física del invernadero del hôtel Saccard, paradigma de las conquistas técnicas de una época, para terminar disertando sobre el desarrollo simbólico y actancial de la novela.

Hemos destacado un recurso empleado por el autor para crear ese componente evasivo que nos permite hablar del jardín como lugar donde se anulan las dimensiones: la imitación de los espacios arbóreos tropicales.

Asimismo, hemos puesto de relieve, tanto el potencial erótico de las plantas aquí presentadas, como las nociones de monstruosidad que suscitan, lo cual no solo evoca la sexualidad perversa que se vive en ese invernadero, sino también la corrupción del Segundo Imperio.

La originalidad de la percepción del espacio en la obra de Zola reside en la dimensión mítica que otorga a los lugares, de forma que estos llegan a determinar el comportamiento de los personajes. Así, lejos de ser simplemente el marco de la narración, 
el invernadero del hotel Saccard es el verdadero desencadenante de la trayectoria vital de los protagonistas.

\section{NOTAS}

${ }^{1}$ Este artículo retoma algunas de las ideas principales de una tesis defendida en 2016 en la Facultad de Filología de la universidad Complutense de Madrid.

${ }^{2}$ Las citas de esta obra que a continuación se incluyen están referenciadas a la edición de 1970 de GF Flammarion, con prólogo de Claude Duchet. 


\section{Bibliografía}

Allain, Y.-M. (2010). Une histoire des serres: De l'orangerie au palais de cristal: Quae.

Allain, Y.-M. y Christiany, J. (2010). L'Art des jardins en Europe, de l'évolution des idées et de savoir-faire, Paris: Ed. Citadelles \& Mazenod.

Beaudoin, N. (1998). La Peur de l'homme et ses manifestations à travers le thème de la femme. Études du discours social inscrit dans trois romans d'Émile Zola: La Curée, Porbouille, Nana.

Becker, C. y Lavielle, V. (1999). La Curée. Paris: Bréal.

Calatrava, Escobar, J. (2011). Jardines de Émile Zola. En Jardín y paisaje. Miradas cruzadas. Madrid: Abada.

Charvoz, J.-C. (1980). Le Monde imaginaire d'Émile Zola d'après les Rougon-Macquart. En Le Retour du mythe. Grenoble: Presses Universitaires de Grenoble.

Got, 0. (2002). Le Système des jardins dans Le Rêve. En Les Cahiers naturalistes, 76. 85-96.

Hemmings, F.W.J. (1966). Émile Zola. Oxford: Clarendon Press.

Rabaté, E. (1989). La Curée de Zola: le sens de métaphores. En littérature, no 75, La Voix, le retrait, l'autre. 112-123.

Sánchez Luque, María Custodia (2016). Los jardines "pintados » de Émile Zola, lugares de encuentro entre literatura y arte. Tesis de doctorado. Universidad Complutense de Madrid.

Tonard, J.-F. (1994). Thématique et symbolique de l'espace clos dans le cycle des RougonMacquart d'Emile Zola. Paris: Peter Lang.

Veloso Santamaría, I. (1993). Grandes espacios zolianos. En Revista de Filología Francesa. 
Maria Custódia Luque est Docteur en philologie - avec mention de doctorat international et excellente cum Laude-, après avoir lu la thèse Les jardins peints d'Émile Zola, des lieux de rencontre entre la littérature et l'art. Ses intérêts de recherche sont: littérature comparée (littérature et peinture); intermédialité; littérature française du XIX siècle. Quelques travaux publiés dans le cadre de ces lignes de recherche sont: "L'inclusion de la notion de mythe dans les descriptions de la serre de l'hôtel Saccard dans «La Curée» d'Émile Zola". Revista Thélème, 2017, n 33; et “L'Eau dans «La Curée» d'Émile Zola comme reflet de l'âme de sa protagoniste Renée Saccard”. Actes du XXV Colloque AFUE, 2017. 